\title{
Social service managers and student information provision
}

\author{
Trish Hanlen
}

Trish is the Convenor of Social Work at the University of Waikato, Tauranga, Member of Aotearoa New Zealand Association of Social Workers and a registered social worker. She is a Member of the New Zealand Order of Merit for services to the community. Her research interests are in the voluntary sector, management, fieldwork placement and child neglect.Trish can be contacted at Patricia@waikato.ac.nz.

\begin{abstract}
Information about students is important to social service agency managers when they consider the question of fieldwork placement provision. This article addresses how student information may influence social service agency managers' decision making towards hosting a student in a non-statutory agency. It draws upon a study of 13 social service agency managers in provincial Aotearoa New Zealand, which involved participants in two separate but consecutive interviews. The findings from this interpretative qualitative study, utilises an eco-systems theoretical framework. Information about students' personal, cultural and educational characteristics and their interest in social services provide important information that influences managers' decision-making toward provision.
\end{abstract}

\section{Introduction}

It could be argued that managers have little involvement with fieldwork placement and indeed the literature suggests that there are three major players, the student, supervisor and the school of social work. It is contended that managers have been left out of the picture for too long and their inclusion is vital to the provision and success of social work fieldwork. The supply of information to the social service manager is an important part of the process of securing a student fieldwork placement. An Aotearoa New Zealand qualitative study sought to understand how information from schools of social work influenced non-statutory managers' willingness towards field work placement provision. Social service managers have seldom been studied for their contribution to fieldwork placement, nor have those from non-statutory organisations. Yet the voluntary social service sector, non-government organisations (NGOs), faith-based, iwi, Māori and self help groups with paid staff are most likely to provide student placements, more so than government agencies (Joint Working Party Report, 2009). Although social work student supervisors are vital to a student's learning, it is argued that the managers are the formal gatekeepers of fieldwork placement provision, the human and material resource keepers with overall authority, power and responsibility for the volume and nature of the student learning which takes place in their agency.

The study increased understanding of the need for robust information about students to enhance management decision making about fieldwork placement provision. Not only did 
managers expect to be involved in the fieldwork placement process, they have expectations of receiving full information about any student they decided to place in their organisation. Expectations included personal information for administrative purposes, cultural affiliations and geographical connections. There were expectations of an interview selection process by which information about a student's interest in learning about the field of practice, their relational skills and abilities as well as their shortcomings could be ascertained. Personal information such as Police, traffic and driving records were also of interest to the managers to inform their decision making, often made in conjunction with other staff such as supervisors. Educational attainment in terms of years of study completed by a student related to the managers' perceptions of a student's ability to contribute to the work of the agency. Lack of information, uncertainty about information or information gaps were perceived as impacting upon the decision-making process and these gaps influenced how the request for placement was responded to.

Fieldwork placement is synonymous with or associated with the terms 'placement', 'field education', and 'practicum' (Dent and Tourville, 2002). The school of social work terminology in this context refers to social work departments / disciplines within universities, polytechnics, private training establishments, colleges and wananga (Māori translation for University). The fieldwork placement literature written mainly by educationalists refers to universityagency relationships, but the findings in this study may be more relevant to polytechnics or wananga because many are located in the provinces where this study was conducted. The study described here was carried out at a time of transition of many institutions changing from two-year diploma programmes to three-year degree programmes.

\section{Qualitative research method, design and methodology}

The focus of this work is drawn from an interpretative study utilising an eco-system framework designed to understand the views of non-statutory social service managers of medium-to-large social services from the provincial, semi-rural and urban centres in both North and South Islands. The 13 participants were drawn from randomly selected social service agency lists from regional and local area sources. The sample was stratified to ensure one iwi social service was included in each of the five provincial areas from which participants were drawn. Twenty-four semi-structured interviews were held. The random selection resulted in an even split between Māori and non-Māori participants, men and women. To increase robustness in design, two sequential interviews of each manager were conducted for a pragmatic purpose of capturing requests for placement 'in motion' and their subsequent reflections on the primary and subsidiary questions. It was theorised that managers would likely receive a variety of requests from competing social service education providers, where willingness or unwillingness responses would be required.

The study design endeavoured to incorporate Te Tiriti o Waitangi and social justice principles such as inclusion, fairness, participation, human rights and social justice with dignified transactions in data collection and simultaneously the development of relationships with participants. Ethical approval was gained from Te Wananga o Aotearoa, New Zealand and Curtin University of Technology, Perth, Western Australia.

Systems theory aided understanding of information management systems as well as increasing understanding of how and why the educational placement system either crosses 
or fails to cross boundaries into an agency system. Multi-level analysis of systems and structures was also useful in organising the literature, data and discussion of the thematic discourse on the findings. Eco-systems analysis contributed to understanding how different systems must be interdependent and are influenced by the cultural notion of reciprocal information exchange, the seeking of common good and equality as it applies to fieldwork placement. Functionalist discourses aided the examination of the pivotal roles and specialist tasks of co-ordinators involved in the fieldwork placement information sharing and decision-making process with managers. Systems theory application would suggest that the co-ordination task is under-estimated as it requires timely and accurate informational, social and educational transaction for what O'Connor, Wilson and Setterlund (1999) call 'negotiating across difference' (p.194).

\section{Literature review}

Field education 'is acknowledged as the crucial component in the education of social workers' (Noble, 2011, p.3). As Zastrow (2003) states:

Field education is an integral component of social work education anchored in the mission, goals and educational level of the program. It occurs in settings that reinforce students' identification with the purposes, values and ethics of the profession, fosters the integration of empirical and practice-based knowledge and promotes the development of professional competence (p. 25).

Fieldwork education as a universal expectation of social work educators has been described by Shardlow and Doel (1996) as the 'heartbeat' (p.24) of social work practice. Ideally, the placement of a student in an agency will result in the student feeling inspired by the possibilities of future professional practice (Shardlow \& Doel, 1996). However, Hay, O'Donoghue and Blagdon (2006) identified a barrier to placement access in that they said managers needed to be encouraged to appreciate the merit of a student's need to learn from the field. These writers indicate that despite the rapid increases in social work and welfare programmes, bringing increased student numbers, there is a decrease in the actual numbers of agencies willing or able to undertake partnerships with social work educational providers.

Despite an international commitment to fieldwork in social work, seasonal uncertainty for schools of social work around student placement availability prevails internationally (Clare, 2001). Scarcity of places for students has been noted for well over a decade, (Noble, Heycox, O'Sullivan \& Bartlett, 2005; Maidment, 2001; Briggs \& Cooper, 2000; Cooper \& Crisp, 1995; Jarman-Rohde, McFall, Kolar \& Strom, 1997; Shardlow \& Doel, 1996; Raskin, Skolnick \& Wayne, 1991). Further, shortages have been exacerbated by an increase in the number of social work programmes (Noble, Heycox, O'Sullivan and Bartlett, 2005). Hicks and Maidment (2009) suggest that at the allocation point a student's 'wish list' is often demolished and consequently impacts upon subsequent relationships with the agency. On the other hand, Connolly and Rathgen (2000) noted that many students were mature with considerable life and work experiences, which they considered needed more hands-on challenging placements, thereby posing a challenge for co-ordinators. Further, these writers state that finding work during or upon graduation was important to mature students loaded down with student fees, who were exceedingly motivated to be allocated a place where a job could result. 
Although the Australasian fieldwork placement literature is relatively rich in fieldwork and student supervision literature, there is a limited amount on the information sharing process prior to student provision interconnecting with social service agencies and their needs.

\section{Findings on personal, cultural and education informational needs}

It is argued that managers play an important role in fieldwork provision, its resourcing and involvement in the preliminary informational exchange process before placement. This important educational component is pivotal to the development of student skills, attributes, competencies and the integration of social work theory with social work practice. However, professional competence learning is dependent on the voluntary goodwill of the social service agency manager to support the student or allow a staff member to do so as a supervisor. This provision of hosting what is frequently a three-month period of learning in Aotearoa New Zealand is provided freely without money changing hands, therefore dependent upon goodwill.

Some managers in this study felt the proposed timing of the request was important information, because of the fluid seasonal service demands on their agency and there was need to plan ahead, well before the designated placement period. My study identified that managers on average received five requests for placements from social work and other disciplines in a six-month period. Managers therefore responded from a position of choice because of competition, or on a 'first come, first served' basis. The reputation of the requesting school or nature of the discipline could stop the negotiation from progressing further. It can be assumed from the findings that when managers know they have choices to make, their attitudes towards the institution, the nature of their students, the relationships they have with individuals within the institution, may influence their responses to requests for student placement.

The supply of basic personal student information such as a student's name, address, and contact details; Police vetting status; driver's licence; supervision arrangements and educational attainment level are details required by non-statutory managers before decisions are made. An extensive amount of information about the potential student was expected and was seen as critical. Personal student information required by the manager on potential student(s) included tribal affiliation, student interests and preparedness, student attributes, student learning style and skills, potential student fit with agency philosophy and agency staff, along with the risks and benefits of particular students to their agency.

Some agencies require certain knowledge and skill sets for particular student placements. Fieldwork placement willingness in some instances was because the managers knew the staff or they wished to aid the struggle for placements or more importantly to select students as potential employees. Unwillingness to provide placements was indicated by various managers because of 'bad' experiences with students in the past for a variety of reasons. Information given to the managers was evaluated for its relevance to the agency and any warning indicators identified, which was described by one manager as them looking for a 'red flag' student or one they would be cautious in accepting. Although it was seen as important to 'go on the trust of the co-ordinator pre-placement matching' said one manager, she expected co-ordinator integrity as it affected future decisions about the school and its students. As Maidment, in Connolly (2001), states, co-ordinators from the school of social work have 'an integral part to play informing and maintaining these unique types of educational relationships' and ideally 'the liaison role and on-course tutoring role are performed by the 
same staff member, rather than being separated as is the norm' (pp. 271-290). Fortune (1994) too, suggests that these linkages are vital especially when trouble arises with students during the placement.

These managers indicated that they needed to know basic administrative information such as school contacts; the school's expectations of them, such as the amount of paperwork required; accountability and supervision expectations. There was a preference for initial information to be received in the form of a CV or Resumé to inform a selection interview between student, manager and possibly others:

I prefer to meet the person, I find it so stressful if it does not work, and life is as stressful as it is - important that it works. I am quite fussy about who I accept. Some students are awesome; some have no or little experience, sometimes it is where they are up to in training, some is to do with personality. My decision is not just bringing a person in, but it is about bringing a person into the equation.

Managers assume that the school's placement co-ordinator has carried out an arbitrary matching and allocation process of students' preferences to identifiable and what was deemed as appropriate agencies, through compatibility and capability matching, before an approach was made to the agency. A point of concern, indirectly related to the matching and allocation process, was expressed about the standard of student suitability for the profession, because 'some people will not get jobs, [because of their] backgrounds, unresolved issues of their own. Some students are not really employable.' Some managers spoke from experience of such students and, while questioning their employability, they were also questioning their learning ability and how they could contribute to the work of the agency.

Managers needed assurance that the student would be a suitable match with the agency staff; that the student was trustworthy and capable. A selection interview or hui or meeting enabled the agency to check commitment to the hours of work and to the agency, supervision arrangements and how they could assist the student to achieve their qualification. In provincial centres, the applicant is likely to be known to the manager or by other staff at the agency, but, in saying this, they were willing to consider persons unknown to them. Although there was some variance in the responses about student information required, managers were keen to receive more student information than had been offered in their past experience of students.

\section{Information on cultural expectations}

Cultural expectations found in this study indicated a need for 'some rigour put into pre-placement meeting, similar to job application to amplify agency and role expectations' therefore tauira (student) placement preparation was about a mutual te kanohi ki te kanohi (face-to-face) meeting, relationship building and a selection process based on relationships rather than via technology or letters. Māori managers sought an early opportunity prior to placement to ask about family and whānau (extended family) connections and to identify whether the student was personally aware of their own identity and heritage. The findings suggest that Māori managers firmly focus on a student's ability towards 'making the connection' with iwi, hapu and whānau, and students who were comfortable in establishing these links in the te kanohi ki te kanohi (face-to-face) tradition. Whether a student or staff member was local, from the local rohe (district) or not, it was the value of connections that mattered. 
To make decisions I need to know who they are, whakapapa - Tainui, Ngapuhi, Ngatiporou (tribal groups). I have wide understanding of [tribal] links. They must be willing to learn, willing to participate in all sectors [of our work].

Moreover, Māori managers appear to have a Māori development focus in helping local iwi, and had a preference for 'local students who will be giving back to our community.' The importance of reaching for cultural identity as expressed in this quote, it indicates it is about respecting indigenous understanding in practice by 'recognising the significance of historical relationships, appreciating the importance of narratives in constructing and sustaining cultural identity, and becoming familiar with the complex concepts associated with Māori well-being' as described by Ruwhiu (2009, p.116). These managers indicated how important it was for students to have, or be willing to extend iwi affiliations and whakapapa (genealogy) linkages and able to make relational connections. Whether managing Māori agencies or not, these managers indicated the importance of receiving information which contained iwi affiliations, prior to meeting the tauira (student). As a Maori manager of a Christian social service said:

We ask about whakapapa (genealogy) of students. However the children we work with have little knowledge of their whakapapa, they are Child Youth and Family children whose parents often were Child Youth and Family children, who have lost their links. Parents are usually between 20-38 years - these are the people no one else will work with. What we need from students is 'respect for differences' willing to work in a respectful way with people who are different.

These quotes suggests that Māori managers are likely to ask students about their cultural identity before they ask any other questions; therefore these individuals are seen as part of the wider system of whānau or extended family. As Ruwhiu (2001) says, whakapapa (geneology) is about the whānau who are traditionally part of the macro system. Although a student's knowledge of their whakapapa may not be broad, their viewpoint and current knowledge is considered valid to these managers. Even if a student's whakapapa knowledge was limited because they were not from the local area, it was acceptable as long as they were willing to learn. The managers in this study stated that students needed the skill to work with difference, make connections with clients and the wider community, particularly iwi, with whom they primarily worked. Inherent in the process were the expectations that staff would be willing to help the tauira (student) make further connections or discover the unknown. Māori managers expected that connection making involved the sharing of whānau (extended family) information with staff members at a meso level of individual and family to allow for such development, which draws from the notion of reciprocity within the organisation. The study findings suggest that Māori managers deliberately choose a pathway format of decision making guided by cultural traditions such as committing to awhi [support] for those tauira (students) who are disadvantaged or found it difficult to enter a placement. Serendipitous findings from the study into factors that influence fieldwork placement provision, found that Māori managers had a generosity of spirit, willingness to teach, willingness to forgive mistakes of the past of students known to them, were disposed and prepared to give 'one hundred per cent to a student to draw out their special gifts.' Information about cultural knowledge and whānau links or willingness to extend these were desirable student requirements that Māori managers were seeking. Māori managers in this study sought students who could build relationships and establish cultural connections, all students, not just Māori students. 


\section{Information on educational attainment}

A significant finding in this study is an increasing understanding of how the number of years a student has been in tertiary education influences willingness towards fieldwork placement. Managers in this study saw first-year tertiary students as 'just tending to hang out' with little local networking knowledge, while another thought they were 'a waste of time, as they were observers who do nothing' because of 'not enough study; not ready - do more damage; this precludes them from being given client work' with the agency striving to be 'protective of clients'. As described by another manager: 'It's like the analogy of a construction firm who had carpentry apprentices who weren't allowed to use their tools but could only observe - it wouldn't happen! This is largely because a social service is a 'business' and needs to be managed as such, so having a 'non-contributor' is nonsensical'. It would appear that lengthy placement periods were considered a long period of time and trial, if the student was in their first year of training.

Some managers indicated that they would only take second year of study students as 'they know more about what we are about and have more tools to undertake some work. We like more senior students in terms of getting stuff done. We prefer maturity as they have been through the first year, show more initiative, although it is important to have a senior working and planning with them to get them through'. Another manager thought some second year of study students 'are onto it and others need experience to be gathered'. The majority of managers thought such students were much more useful to the organisation and had a wider range of skills to offer the agency.

Managers who had experienced third and fourth year of study students indicated that they would prefer them 'as they are more capable and have done a placement already' indicating 'the later the better' was their preference. The usefulness of the student contribution to the agency was very clear, as they preferred a student who could run a programme and accomplish set tasks by showing initiative.

Fieldwork placement in many instances was considered a trial period to ascertain the fit of a student as a future employee who could be relied upon to step up, in periods of high staff turnover. 'The lifecycle of the social worker appears to be approximately two years in my experience in the NGO (non-government organisation) sector' was one manager's view. Just as a stressful environment was identified by this manager, so too was the resolve to avoid students who brought or created further stresses not only for the manager personally, but in the agency environs. It would appear from past experience it took managers time to know the student personally and be able to rely upon them. The findings indicated that safety uncertainty was created when it was unclear whether the student had been vetted recently by the school for criminal records. Eight managers carried out Police checks on the students upon their arrival on placement for this reason. Some managers resented having to carry out the Police vetting task for the limited time the student was with them, particularly as they knew there would be a considerable delay in receiving the results, with potentially embarrassing consequences. Some managers said they presumed that schools had recently conducted satisfactory checks on students. Some were unsure about whose responsibility it was for the process as they had received no information, so had followed agency protocol for staff recruitment and 
carried it out. This procedure needs attention as it caused confusion and is also likely to do so for students. If a student has an item on their record they were ashamed of, their learning is likely hampered by anxiety until the results come back, particularly if they have chosen not to share pertinent information. The double up on this procedure appears to cause resentment by the managers by adding an additional task to their already high workload. These results might mean that both institutions are carrying out the same process for the same purpose in the same year, which suggests an inefficient use of time and misuse of a free service provided by the New Zealand Police. Such a mismatch in communication potentially exposes managers and their non-statutory agency to an unidentified risk. On one hand there is a duty of the school to share information (Hicks and Maidment, 2009), but on the other it is argued by these writers that this creates challenges to educational institutions to manage a student's right to privacy. It is assumed from this study that agency management has the right to be informed of potential risks either by the school or the student prior to acceptance of a student on placement. It is clear that lack of information about the presence or absence of a Police record could contribute towards reluctance in accepting a student. This finding adds to Furness and Gilligan's (2004) suggestion that sensitive personal information should be shared about issues which will impact on placement work, but they also believe information sharing must have the student's permission before selection takes place. It is interesting to note that Brodersen, Richman and Swick (2009) in considering risks and mitigating factors in decisions to accept students with criminal records, found that students would be rejected for crimes such has homicide $(93.8 \%)$; child molestation (93.8\%); forcible rape $(89.9 \%)$ and other serious crimes, whereas underage drinking (3.6\%); driving under the influence $(19.3 \%)$; possession of stolen goods $(30.6 \%)$ and other less serious crimes by students were less likely to be rejected by the 280 field supervisors in the Brodersen et. al. survey. These researchers also found that criminal records were more likely to take precedence over students' personality characteristics in acceptance or rejection of students, therefore information on criminal records is vital for a manager's decision making. Concern about student convictions could relate to Kemshall's (1997) argument that social services are increasingly preoccupied with the desire to avert and manage risk, which rightly is a manager's responsibility.

Although of a lesser association with information on criminal offending are records relating to the holding of a driver's licence and a student's ability to drive a vehicle safely whilst on placement. The results were inconclusive as to whether the possession of a driver's licence affected placement provision decision making. Eight managers required a student working in their agency to hold a licence while five did not. Some managers thought it was essential to carry out their work. On the other hand, young students driving cars were said to attract high insurance premiums due to being under 25 years of age and therefore managers discouraged driving by such students. Other managers said they had informal policies about not sending students out alone in cars. The student's licence holder status is also information that should be shared with managers initially, as managers would wish to avoid embarrassment about accepting a student on placement and then finding out the student could not carry out the tasks in the education plan, therefore re-creating a new education plan. This situation would likely create resentment towards the educational institution, if managers and supervisors had assumed a student could drive a workplace vehicle. It is therefore argued that a co-ordinator of student placement would likely enhance the likelihood of positive 
decisions towards provision if such information is provided prior to provision. Information from the school was vitally important to these managers; information that was screened, interpreted and evaluated for its relevance to the decision-making process and needs of the agency, with any concerns identified that might be relevant to the manager or their supervisor.

\section{Information about student supervision and managers' expectations}

Just as education duration was important information for managers, they also needed the school to know their expectations around supervision, particularly their views about external supervisors coming into the agency. As the majority of the managers in the study under focus had previously or regularly undertaken the student supervisor role, there was less need to find a supervisor from their staff. There was a preference to supply a supervisor so all tasks could be filtered through this supervisor to avoid work being 'chucked at student from all directions and to avoid the student treated as a 'dog's body' '. However, one manager thought it appropriate to have an external supervisor to assist her when her workload was under pressure. Preference was indicated for internal supervisors over external ones, as some felt external supervisors may have gaps in their knowledge about the way the organisation functioned, or may not understand the ethos of strength-based work or family work or they were not a good match and possibly cause confusion for the student. Another manager thought that if all supervision was external, the student needed a direct connection with the work of the agency, therefore needing an internal supervisor as well. As articulated by another manager, 'external supervisors may not be able to relate to the organisation or what the student is doing'. The study findings suggest that if an external supervisor is to be appointed the managers want to be consulted about the appointment to ensure a match with the agency staff and philosophy. The quality and credibility of an external supervisor was an important information factor for these managers.

As Maidment and Woodward said in Shardlow and Doel (2002, pp.94, 95), an external supervisor has to understand the agency culture, its group of clients and be able to assist the student integration as they had an impact on the teaching and learning. Doel and Shardlow (1996, p. 16) suggest that the vast majority of supervisors are agency based. Bogo and Power's (1992) study showed personal satisfaction with teaching (94\%), contribution to the profession (92\%), sharpened practice skills (94\%) with relief of job boredom and connection to the university as being satisfying for more than $60 \%$ of the sample of supervisors in that study.

\section{Discussion on decision-making, information and bounded rationality}

It could be argued that more information may not change the decisions of managers. But according to Gray, Plath and Webb (2009) all relevant evidence is seldom retrieved or received and judgements are more likely to be made on relevant information accessible in memory (Bodenhausen and Wyer, 1987). Nevertheless the weight of information is important. It has been argued here that final placement decisions are made by a manager, the legitimate holder of the resources. These decisions may be made under pressure, which may or may not result in what Hughes and Wearing (2007) calls 'poor decisions' because they suggest 'poor decisions are more common' if 'there is uncertainty over information'(p.86) 'or when 
there are questions about the quality or reliability of the information' (p.84). When information is scant with few options it would appear that 'additives' are added according to Weiten (2002). Further, Simon's (1957) reasons that lack of information, problem complexity, limited information processing capacity of individuals, short time frames for decision making and divergence and conflict between organisational goals, is bounded and constraining for decision making.

In the social work fieldwork context, indicators of 'good' decisions are dependent upon clear information supplied to the managers on student characteristics, coupled with their past experiences of students; relationships being remembered; manager's judgement of the organisational context at the time the request is made; and their positioning of making competitive choices in times of scarcity.

\section{Conclusion}

It could be argued that this has all been said before, but the literature is scarce on the contribution of non-statutory agency management to fieldwork placement provision. Social work obligations flowing from the Treaty of Waitangi are important professional edicts in Aotearoa New Zealand. These embrace a will to support things Māori and indigenous development which includes an understanding of the needs of Māori (pan tribal) and iwi (tribal) social services. Just as whānau holds Māori culture together with established values, tikanga and kawa, Māori or pākēha cultural norms become ingrained and therefore managers' search for information and decisions are shaped by culture. The findings of this study suggest that the way non-statutory managers understood their organisational needs for information and their decision-making role with fieldwork placement provision was influenced by culturally bound norms, beliefs and values. These findings suggest that the greater the student information fits the organisational need the easier it is for managers to decide on fieldwork placement provision. The richness of initial basic information from the school; its support systems for students and the agency; and the nature of student matching and selection processes in meeting agency needs were important informational factors influencing managers' decisions towards student placement. Personal, cultural and educational information was required by managers to aid their decision about potential student(s). The results suggests that information related to a student's tribal affiliation, interests and preparedness to learn, attributes, knowledge and skills were required to inform managers. A potential student fit with agency philosophy and agency staff, along with information about the risks and benefits of a particular student, was information sought by social service managers. The doubling up of tasks in relation to the Police vetting process potentially expose agencies to unidentified risk through uncertain information provision. Enriched information and involvement with the contracting of external student supervisors was a consideration as managers preferred student supervisors with in deep knowledge of their organisation and the theories and models they used. The non-statutory social service managers in this study expected more student information from the schools of social work than they had received in the past as competition for placements positioned them for choice.

\section{References}

Bodenhausen, G.V., \& Wyer, R.S. (1987). Social cognition and social reality: Information acquisition and use in the laboratory and the real world. In H.J. Hippler, N. Schwarz, \& S. Sudman (Eds.). Social information processing and survey methodology (pp. 6- 41). Berlin: Springer. 
Bogo, M., \& Power, R. (1992). New field instructors' perceptions of institutional supports for their roles. Journal of Social Work Education, 28(2), 178-189.

Briggs, L., \& Cooper, L. (2000). Overview of responsibilities of fieldwork management. In L. Cooper \& L. Briggs (Eds.). Fieldwork in human services. St Leonards, NSW, Australia: Allen \& Unwin.

Brodersen, M., Richman, J., \& Swick, D. (2009). Risks and mitigating factors in decision to accept students with criminal records. Journal of Social Work Education, 45(3), 349-363.

Clare, B. (2001). One practitioner's reflections on the reconstruction and re-conceptualization of social work: A response to McDonald \& Jones and colleagues. Australian Social Work, 54(1), 103-107.

Connolly, M. (Ed.) (2001). New Zealand social work contexts and practice. Auckland: Oxford University Press.

Connolly, M., \& Rathgen, E. (2000). Social work students: Readiness for practice and issues for the field. Social Work Review, XII(2), 13-16.

Cooper, L., \& Crisp, B. (1995). Field educator turnover: A challenge to the quality of field education. Paper presented to 2nd National Cross Faculty Practicum Conference, Australia.

Dent, H., \& Tourville, A. (2002). University - community partnerships. In S. Shardlow \& M. Doel (Ed.). Learning to practise social work: International approaches (1) 1-16. London, UK: Jessica Kingsley Publications.

Fortune, A. (1994). Field education. In F. Reamer (Ed.). The foundations of social work knowledge (pp. 151-194). New York, USA: Columbia University Press.

Furness, S., \& Gilligan, P. (2004). Fit for purpose: Issues from practical placements, practice teaching and the assessment of students' practice. Social Work Education, 23(4), 465-479.

Gray, M. Plath, D., \& Webb, S. (2009). Evidence-based social work A critical stance. London, United Kingdom: Routledge.

Hatch. J. (1997). Leadership, decision making and risk. Organisation theory: Modern, symbolic and post modern perspectives. New York, USA: Oxford University Press.

Hay, K., O’Donoghue, K., \& Blagdon, J. (2006). Exploring the aims of social work field education in the registration environment. Social Work Review, 18(4), 20-28.

Hicks, H. \& Maidment, J. (2009). Fieldwork practice in social work. In M. Connolly, \& L. Harms, (Eds.). Social work contexts and practice (2nd ed.). Melbourne, Australia: Oxford University Press.

Hughes, M., \& Wearing, M. (2007). Organisations and management in social work. London: Sage Publications.

Jarman-Rohde, L., McFall, J., Kofar, P., \& Strom, G. (1997). The changing context of social work practice: Implications and recommendations for social work educators. Journal of Social Work Education, 33(1), 29-47.

Joint Working Party. (2009). Social work education in New Zealand. Unpublished Joint Working Party Report received by Aotearoa New Zealand Association of Social Work Educators, Christchurch: initiated by the Tertiary Education Commission.

Kemshall, H. (1997). Risk, social policy and welfare. Buckingham, United Kingdom: Open University Press.

Maher, C., \& Burke, T. (1991). Informed decision making. Melbourne, Australia: Longman Cheshire.

Maidment, J. (2001). Fieldwork practice in social work education. In M. Connelly (Ed.) New Zealand social work: Contexts and practice. Auckland: Oxford University Press.

Maidment, J., \& Woodward, P. (2002). Student supervision in context: A model for external supervisors. In M. Shardlow \& M. Doel (Eds.). Learning to practise social work: International approaches (1), 25-42. London: Jessica Kingsley Publishers.

Noble, C. (2011). Field education: Supervison, curricula and teaching methods. In C. Noble \& M. Henrickson (Eds.). Social work field education and supervision across Asia Pacific. Sydney, Australia: Sydney University Press.

Noble, C., Heycox, K., O'Sullivan, J., \& Bartlett, B. (2005). Work-based practica: Real learning or just your usual job? In P. Camilleri \& M. Ryan (Eds.). Advances in social work and welfare education, 7(1), 98-109.

O'Connor, I., Wilson, J., \& Setterlund, D. (1999). Social work and welfare practice (3rd ed.). Melbourne, Australia: Addison Wesley Longman, Australia Pty Ltd.

Raskin, M., Skolnick, L., \& Wayne, J. (1991). An international perspective of field education. Journal of Social Work Education, 27(3), 258-270.

Ruwhiu, L. (2001). Bicultural issues in Aotearoa New Zealand social work. In M. Connolly (Ed.). New Zealand social work context and practice. Auckland: Oxford University Press.

Ruwhiu, L. (2009). Indigenous theories in Aotearoa New Zealand. In M. Connolly and L. Harms (Eds.). Social work context and practice (2nd ed.). Victoria, Australia: Oxford University Press.

Shardlow, S., \& Doel, M. (1996). Practice learning and teaching. Basingstoke: Macmillan Press.

Shardlow, S., \& Doel, M. (Eds.). (2002). Learning to practise social work: International approaches. London: Jessica Kingsley Publishers.

Simon, H. (1957). Models of man. New York, USA: John Wiley.

Weiten, W. (2002). Psychology themes and variations (5th ed.). Australia: Wadsworth.

Zastrow, C. (2003). The practice of social work: Applications of generalist and advanced content (7th ed.). Pacific Grove, CA: USA: Thomson Brooks/Cole. 